\title{
IUMRS Announces Call for Initiative Proposals \\ www.iumrshq.org
}

Though they may not know it, members of numerous materials research societies from all parts of the globe have access to a world-wide network of scientists through the International Union of Materials Research Societies. The IUMRS is an association of scientific societies dedicated to promoting interdisciplinary materials research around the world. Founded in
1991, IUMRS now includes over a dozen international societies and several institutional members such as national laboratories. Working to promote materials research on global issues and to connect materials researchers in different countries, IUMRS activities include endorsement of one or two international meetings each year and presentation of the Sōmiya

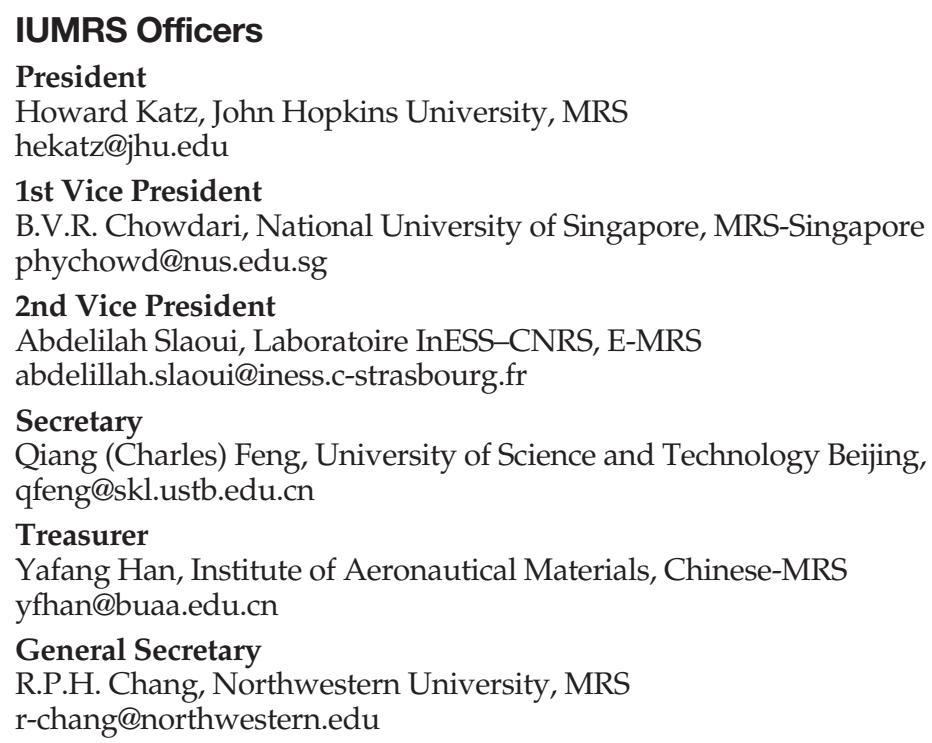

award to recognize notable achievements in materials research.

According to IUMRS President Howard Katz, IUMRS is now seeking to expand the scope of its activities and is calling for proposals from members of the adhering bodies (e.g., MRS, European Materials Research Society, Materials Research Society of India, Materials Research Society of Japan). Suggested ventures for proposals include the organization of international research exchange visits, participation in interdisciplinary policy and science advocacy meetings, authorship of position papers aimed at international policymakers, and the establishment of collaborative research studies and educational efforts. The official announcement of this opportunity, which first appeared in the March edition of Materials360, emphasizes topics relevant to global sustainability, including energy and water supply, as well as promotion of materials research in emerging regions. Through this program, IUMRS is aiming to increase involvement with other international organizations, particularly the International Council for Science, and to foster increased interaction among the constituent groups of IUMRS. Interested parties are encouraged to contact the IUMRS officers.

AlisOn HatT

\section{Handbook of Modern Ion Beam Materials Analysis SECOND EDITION}

The most comprehensive database on ion beam analysis ever publishedrevised and updated from the popular handbook released in 1995!

EDITORS Yongqiang Wang and Michael Nastasi

- Written and compiled by over 30 leading authorities in the field of ion beam analysis

- Important reference tool for technicians, students and professionals

- A must for all accelerator labs

- Excellent introduction to the fundamentals and lab practices of ion beam analysis

- Useful as a teaching text for undergraduate senior or first-year graduate students

- For libraries, the most recent and comprehensive collection of nuclear and atomic data for the

applications of ion beam materials analysis

- DVD includes bonus info-Ion Beam Analysis Nuclear Data Library (IBANDL) and GUPIX

Subroutines (CSA and YLS) for X-ray Database

TWO VOLUME PRINT SET + DVD OF APPENDICES

Order Code: IBH-2 • ISBN: 978-1-60511-217-6

$\$ 200.00$ MRS Members

$\$ 250.00$ Nonmembers

VOLUME 1-PRINT CHAPTERS (441 PAGES) + DVD OF APPENDICES

Order Code: IBH-2a • ISBN: 978-1-60511-215-2

$\$ 125.00$ MRS Members \$150.00 Nonmembers

VOLUME 2-PRINT APPENDICES ONLY (370 PAGES)

Order Code: IBH-2b • ISBN: 978-1-60511-216-9

$\$ 125.00$ MRS Members

$\$ 150.00$ Nonmembers

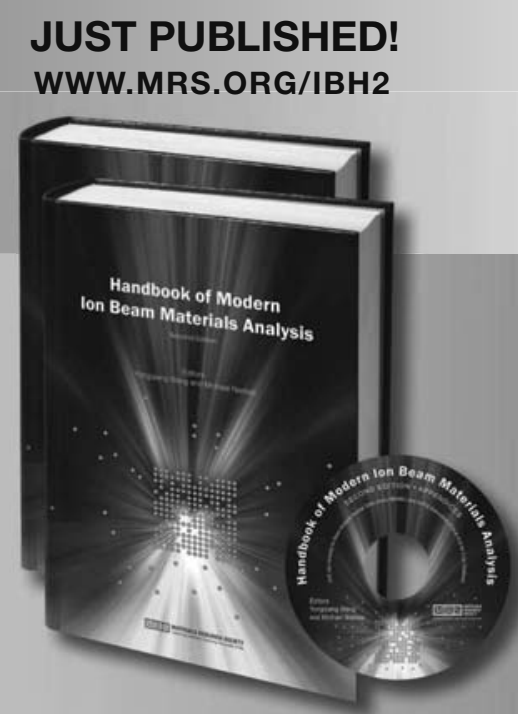

ORDER FROM

Materials Research Society, Customer Services 506 Keystone Drive, Warrendale, PA 15086 USA

Tel 724.779.3003 Fax 724.779.8313

info@mrs.org www.mrs.org//BH2 